Brit. J. prev. soc. Med. (1975), 29, 31-39

\title{
A 12-year study of menarcheal age
}

\author{
D. F. ROBERTS AND T. C. DANN \\ Department of Human Genetics, University of Newcastle upon Tyne and \\ The Medical Centre, University of Warwick
}

\begin{abstract}
Roberts, D. F. and Dann, T. C. (1975). British Journal of Preventive and Social Medicine, 29, 31-39. A 12-year study of menarcheal age. Data on menarcheal age were collected on girls admitted to the University College of Swansea over a 12-year period. It appears that the downward trend in menarcheal age ceased in girls born about 1946 (the 1965 student intake) and that an upward swing may have since occurred. This change in the secular trend is not due to the association of menarcheal age with family size or of position in sibship, or to changes in the regional composition of the student intake. The well established effect of physique remains, but there is no effect of socio-economic status as assessed by the RegistrarGeneral's classification of the father's occupation.
\end{abstract}

Menarcheal age is a biological variable of both biological and social interest for it is affected by both social and biological factors. It was the subject of writings certainly from the early 17 th century onwards, and by the early 1950 s the effects of the main factors influencing it were well established. A particularly intriguing observation in the post-war years was that in girls in Britain, as elsewhere in Europe, menarche had been occurring at steadily earlier ages during the last 100 years. The rate of this secular diminution was calculated to be about three to four months per decade (Tanner, 1955). The continuation of this trend was demonstrated by Tanner $(1962,1965)$ with critical documentation, and various factors responsible for it were identified. It seemed to us to be impossible that this diminution would continue indefinitely, and therefore that it would be of interest to keep a check on menarcheal age in an attempt to detect the first signs of any slackening of the trend in Britain. To do this thoroughly would necessitate a large-scale investigation, taking the form of a yearly inquiry in a group of schools, questioning girls of ages 9-17 years, with subsequent probit analysis of the results. This would be timeconsuming and probably a nuisance to the schools concerned. We felt instead that a small sample enquiry would be useful, using an alternative retrospective method of data collection which, given proper safeguards, can yield reliable results. In 1959 we therefore started to collect data on all girls entering the University College of Swansea in each year. The material thus consists of recall data from a succession of cross-sectional surveys relating to one particular section of the population.

In the medical examination carried out at the time of their admission on all girls entering the University College of Swansea from 1959 onwards, the age at birthday preceding menarche was recorded. The 1970 intake was the last to be included in this study, and, with the exception of the 1963 intake for which this item was not recorded, the data are continuous over 12 years.

Each girl was asked when her menarche had occurred. Such recall data are notoriously liable to error or bias from a variety of sources; they depend on recollection accuracy, intelligence of the girl, composition of the sample in terms of age and pubertal status, and the clarity of definition of the event. Such errors are thought to be minimal in the present data, for the sample relates to girls above average in intelligence and reliability of memory, all questioned between the ages of 18 and 21. There was no girl who had not attained menarche at the time of examination. The majority of the girls were quite clear in recalling the actual month, though the data were recorded as age at birthday preceding menarche for ease of analysis. The very few girls whose answers indicated that they themselves were in some doubt were excluded from the analysis. Other relevant details were also noted, and the following variables were taken into account: 
$Y$ menarcheal age in years, recorded as age at birthday preceding,

$\mathrm{X}_{1}$ year of birth,

$\mathrm{X}_{2}$ number of siblings the girl has,

$\mathrm{X}_{3}$ numerical position of the girl in her sibship'

$\mathrm{X}_{4}$ father's occupation described numerically as in the Registrar-General's classification (despite the weakness of this figure, it was retained in the analysis to give some indication of the socio-economic status, and special care was taken to ascertain the exact type of work performed).

The first analysis was undertaken at the end of the first seven years (Roberts and Dann, 1967). This showed a clear and progressive diminution in menarcheal age, which statistically was highly significant. The rate of diminution was compatible with that observed by Tanner in European and American sources, amounting to about four months per decade over the period 1830-1960. Effects were also shown of family size, position in family, and the physique of the girl. Later menarche tended to occur in girls from larger families, of later position in sibship, and of more linear physique. It was clearly important to continue the survey, and this was done for a further five intakes. Collection of data finally ceased after the 1970 intake, by which time details were available for 2,457 girls. A preliminary note on the study appeared (Dann and Roberts, 1973), and the full analysis of the total is now reported.

\section{Results}

The mean and standard deviation for each variable for each year's intake are set out in Table I. The suggestion that girls of intakes of 1959, 1968, and 1969 come from slightly larger families is not significant. There is a trend ove्ष the years for an increase, which is highly significant in the occupational status of the father; wheth this implies that later intakes are more prepon: derantly from higher socio-economic classes, ox whether it means that more fathers now describe their occupation in a form which places them in better category, is not clear, but the former seen more likely from subjective impressions. Mea position in family seems to have remained fairty constant throughout the period. But particularly noticeable is the fact that the decline in mean menarcheal age, so obvious over the first seven years, has not continued.

The year of intake was considered of less relevancece than the year of birth and was excluded from the following analysis. A multiple regression analysis was performed to examine the association $\overrightarrow{\theta f}$ menarcheal age with the other four variables. The variables $Y$ and $X_{1}$ to $X_{4}$ are as described above, except that $X_{1}$ is year of birth less 1938. The zero-order correlation coefficients are as set out Table II. With the exception of the obvious correlotion between position in family and size of fan all correlation coefficients are low. There is $r$ f significant linear association of menarcheal gige with year of birth or father's occupation; of. father's occupation with family size or position sibship. There is a slight but highly significa positive association of menarcheal age with famif size, and a highly significant negative associatiog with position in sibship. Father's occupation significantly improves with year of birth, the number of sibs increases, and so, barely, does the position in sibship. There have clearly been important secular social trends during this period.

Since the interpretation of such significant be्gt low zero-order associations is open to error if, iss in this case, there is intercorrelation between

TABLE I

VARIATES BY YEAR OF INTAKE

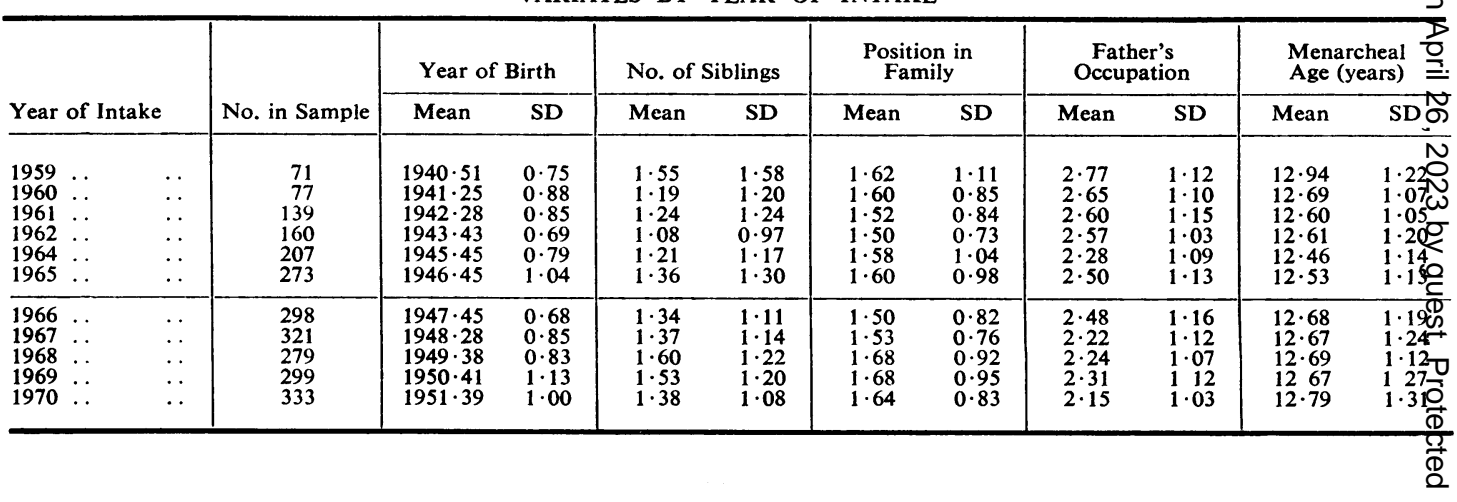


TABLE II

ZERO-ORDER CORRELATION COEFFICIENTS-5 VARIABLE ANALYSIS

\begin{tabular}{|c|c|c|c|c|c|c|}
\hline & & $\mathbf{x}_{1}$ & $\mathbf{x}_{\mathbf{2}}$ & $\mathbf{x}_{3}$ & $\mathbf{x}_{4}$ & $\mathbf{Y}$ \\
\hline $\mathbf{x}_{1}$ & Year of birth $\quad$.. & - & $\begin{array}{l}+0.0647 \\
\pm 0.020\end{array}$ & $\begin{array}{l}+0.0413 \\
\pm 0.020\end{array}$ & $\begin{array}{l}-0.1322 \\
\pm 0.020\end{array}$ & $\begin{array}{l}+0.0164 \\
\pm 0.020\end{array}$ \\
\hline $\mathbf{x}_{2}$ & No. of siblings $\quad$.. & & - & $\begin{array}{l}+0.5734 \\
\pm 0.014\end{array}$ & $\begin{array}{l}-0.0264 \\
\pm 0.020\end{array}$ & $\begin{array}{l}+0.0661 \\
\pm 0.020\end{array}$ \\
\hline $\mathbf{X}_{\mathbf{3}}$ & Position in sibship & & & - & $\begin{array}{l}+0.0035 \\
\pm 0.020\end{array}$ & $\begin{array}{l}-0.0292 \\
\pm 0.020\end{array}$ \\
\hline$x_{4}$ & Father's occupation & & & & - & $\begin{array}{l}-0.0199 \\
\pm 0.020\end{array}$ \\
\hline $\mathbf{X}_{1}{ }^{2}$ & & $\begin{array}{l}+0.9773 \\
\pm 0.001\end{array}$ & $\begin{array}{l}+0.0691 \\
\pm 0.020\end{array}$ & $\begin{array}{l}+0.0458 \\
\pm 0.020\end{array}$ & $\begin{array}{l}-0.1248 \\
\pm 0.020\end{array}$ & $\begin{array}{l}+0.0255 \\
\pm 0.020\end{array}$ \\
\hline
\end{tabular}

$\mathrm{X}_{1}=$ year of birth less 1938

variables, partial regressions were calculated. The regression coefficients (in standard and actual measure) of menarcheal age on each independent variate are shown in Table III, first examining a linear regression of menarcheal age on the other variables and then a curvilinear regression. For the former, the regression coefficients of menarcheal age on number of siblings and position in family are highly significant, whereas those on year of birth and father's occupation are not. The multiple correlation coefficient $R$ is 0.1071 . In the curvilinear analysis, the regression coefficients of menarcheal age on each variate are all statistically significant, except that on father's occupation. There is a slight increase in the multiple correlation coefficient $(R=0.1159)$. The curve may in fact be of some form other than quadratic, but the latter was accepted here for simplicity. These findings may be interpreted as indicating that menarcheal age steadily became earlier in the first half of the survey, but that the downward trend ceased in girls born about 1946 (the 1965 intake), and that an upward swing has since occurred (Fig. 1). Menarcheal age, moreover, tends to be delayed in girls of larger families, and girls born later in a family of a given size have earlier menarche, a tendency independent of the secular trend.

\section{Reality of the Secular Change}

Is this apparent end to the downward trend real, or is it attributable to some quirk of the analysis or of the data? From the statistical point of view the downward trend identified in the earlier analysis in the years 1959-65 was highly significant. But this may nonetheless have been a statistical artifact, accepted as real because of its similarity

TABLE III

PARTIAL REGRESSION COEFFICIENTS OF MENARCHEAL AGE ON EACH INDEPENDENT VARIATE

\begin{tabular}{|c|c|c|c|c|}
\hline Omitting $X_{1}{ }^{2}$ & $\mathbf{x}_{1}$ & $\mathbf{X}_{2}$ & $\mathbf{X}_{\mathbf{3}}$ & $\mathbf{x}_{4}$ \\
\hline $\begin{array}{l}\text { Zero-order correlation of } \mathbf{Y} \\
\text { with } \mathbf{X} \cdots \\
\cdots\end{array}$ & +0.0164 & +0.0661 & -0.0292 & -0.0199 \\
\hline 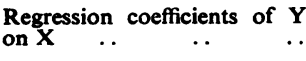 & +0.0040 & $+0 \cdot 1238$ & $-0 \cdot 1346$ & -0.0161 \\
\hline Values of $F(d f 1,2452) \ldots$ & $0 \cdot 27$ & $24 \cdot 81^{x \times x}$ & $16 \cdot 55^{\times \times x}$ & 0.54 \\
\hline
\end{tabular}

\begin{tabular}{|c|c|c|c|c|c|}
\hline Including $X_{1}{ }^{2}\left(=X_{5}\right)$ & $x_{1}$ & $\mathbf{x}_{2}$ & $\mathbf{x}_{\mathbf{3}}$ & $\mathbf{x}_{4}$ & $\mathbf{x}_{\mathbf{s}}$ \\
\hline Zero-order correlation of $\mathrm{Y}$ with $\mathrm{X}$ & +0.0164 & +0.0661 & -0.0292 & -0.0199 & +0.0255 \\
\hline Values of $F(d f 1,2451) \ldots$ & $4 \cdot 18^{x}$ & $24 \cdot 49^{\mathrm{xxx}}$ & $16 \cdot 79^{x \times x}$ & 0.62 & $4 \cdot 87^{x}$ \\
\hline
\end{tabular}




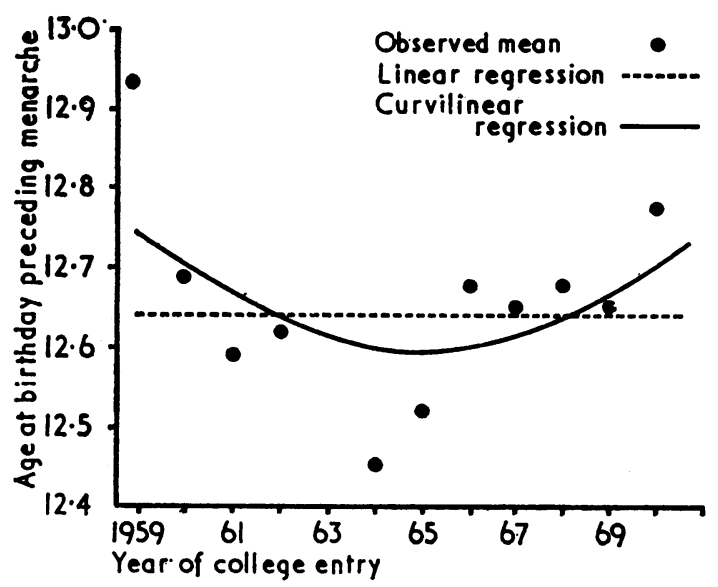

FIG. 1. Regression lines of age at birthday preceding menarche on year of college entry. to what was expected from published data. If thfft trend is regarded as real, then the curvilinear regression here demonstrated has also to be accepte though since the first two samples are numericalfy the smallest, the form of the curve suggested by the means of each year's entry for the total series maty perhaps be rather exaggerated (Fig. 1). If, howevê, the earlier trend in the data is not accepted (f or the quadratic component in the curvilinear assof ciation with year of birth does not reach a very high level of significance), and a linear regression is fitted to the total data instead of a curvilinear then the secular regression line is nearly horizontal, suggesting again that the downward trend in meno archeal age has ceased.

A second possibility is that the apparent secular association is a reflection of some other variable There perhaps may be differences in menarchesf

TABLE IV

SUBSAMPLES BY REGION OF ORIGIN

\begin{tabular}{|c|c|c|c|c|c|c|c|c|c|c|}
\hline & \multirow[b]{2}{*}{$\mathbf{n}$} & \multicolumn{2}{|c|}{ Age at Menarche } & \multicolumn{2}{|c|}{ Height (in) } & \multicolumn{2}{|c|}{ Weight (lb) } & \multicolumn{2}{|c|}{ Ponderal Index } & \\
\hline & & Mean & SD & Mean & SD & Mean & SD & Mean & SD & \\
\hline 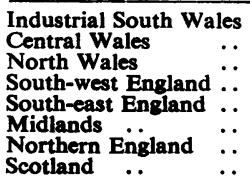 & $\begin{array}{r}759 \\
187 \\
98 \\
194 \\
630 \\
380 \\
194 \\
3\end{array}$ & $\begin{array}{l}12 \cdot 61 \\
12 \cdot 72 \\
12 \cdot 85 \\
12 \cdot 74 \\
12 \cdot 63 \\
12 \cdot 62 \\
12 \cdot 80 \\
13 \cdot 67\end{array}$ & $\begin{array}{l}1 \cdot 25 \\
1 \cdot 13 \\
1 \cdot 08 \\
1 \cdot 14 \\
1 \cdot 16 \\
1 \cdot 23 \\
1 \cdot 18 \\
0 \cdot 58\end{array}$ & $\begin{array}{l}63 \cdot 74 \\
63 \cdot 53 \\
63 \cdot 40 \\
64 \cdot 18 \\
64 \cdot 57 \\
64 \cdot 48 \\
64 \cdot 12 \\
61 \cdot 50\end{array}$ & $\begin{array}{l}2 \cdot 28 \\
2 \cdot 61 \\
1 \cdot 81 \\
2 \cdot 24 \\
2 \cdot 30 \\
2 \cdot 39 \\
2 \cdot 55 \\
3 \cdot 78\end{array}$ & $\begin{array}{l}126 \cdot 06 \\
126 \cdot 10 \\
125 \cdot 77 \\
127 \cdot 29 \\
128 \cdot 80 \\
128 \cdot 34 \\
128 \cdot 56 \\
108 \cdot 00\end{array}$ & $\begin{array}{l}16 \cdot 92 \\
16 \cdot 97 \\
17 \cdot 48 \\
17 \cdot 49 \\
17 \cdot 51 \\
16 \cdot 53 \\
16 \cdot 98 \\
21 \cdot 00\end{array}$ & $\begin{array}{l}12 \cdot 75 \\
12 \cdot 71 \\
12 \cdot 70 \\
12 \cdot 80 \\
12 \cdot 83 \\
12 \cdot 82 \\
12 \cdot 75 \\
12 \cdot 97\end{array}$ & $\begin{array}{l}0.53 \\
0.49 \\
0.47 \\
0.46 \\
0.55 \\
0.50 \\
0.57 \\
0.61\end{array}$ & 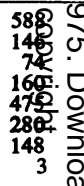 \\
\hline
\end{tabular}

TABLE V

COMPOSITION OF INTAKES BY REGIONS

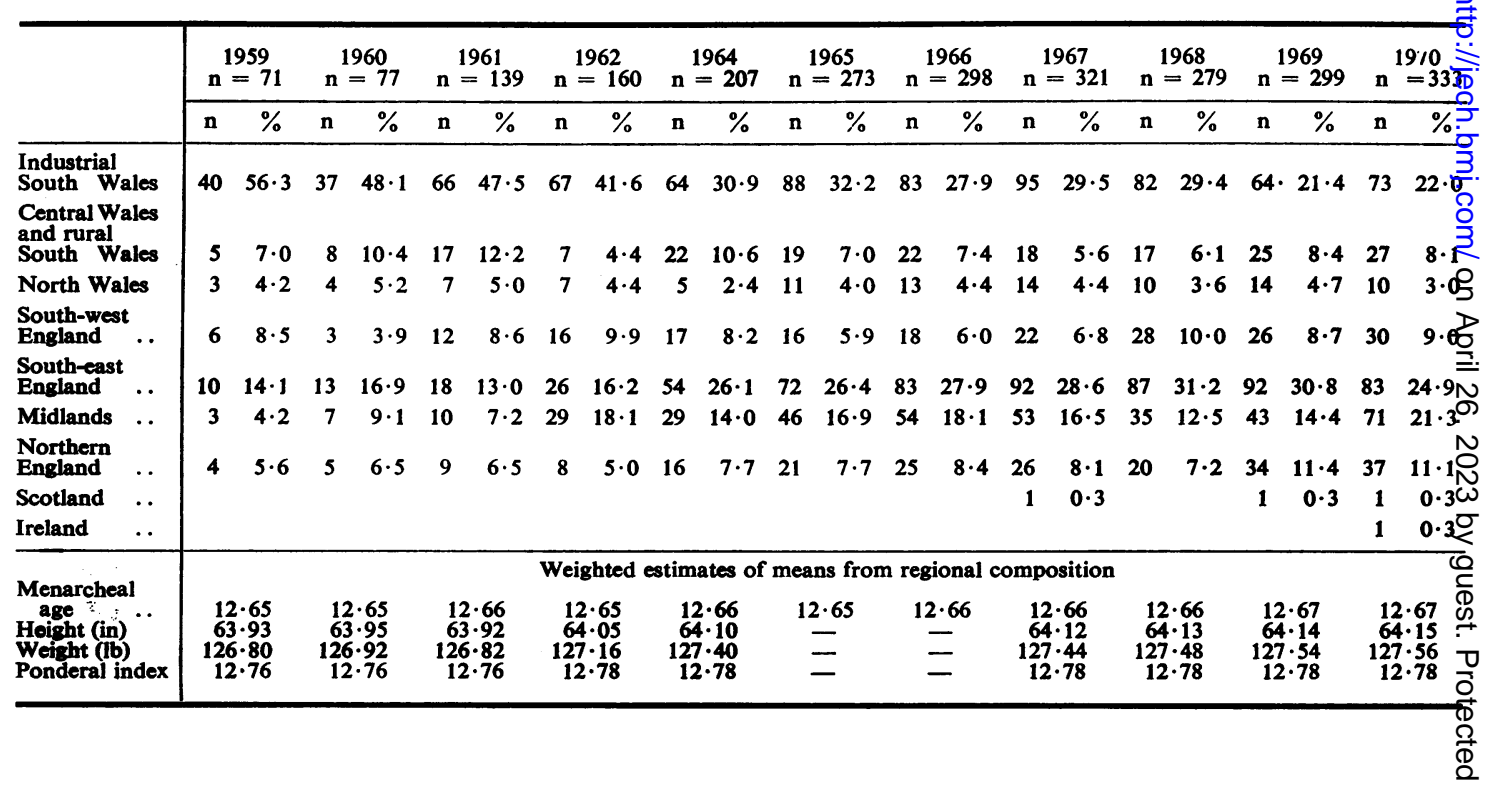


age in different geographical areas of this country; and, if this is so, consistent changes in their representation in the Swansea student intake could produce apparent secular variation. Grouping the data on menarche according to region of country suggests that slightly later menarche occurs in north and central Wales and northern and south-west England, and slightly earlier menarche in south-east England, the midlands, and industrial South Wales (Table IV). Certainly, there have been differences in the composition of the sample (Table V). The proportion from South Wales has decreased and the proportion from England has increased. Calculation of a mean for each year's intake, weighted according to the proportion of girls from each region, shows no trend comparable with the actual means observed (Table V). So differential representation of the regions appears not to be responsible for the observed year to year variation in menarcheal age.

\section{Association with Physique}

Perhaps the secular trend is associated with variation in body build. The relationship of menarcheal age to physique is well established, girls of more linear physique experiencing later menarche. Information on body build is available for the majority of the girls in this study (height and weight were not measured on the 1965 and 1966 intakes). Body build, represented as ponderal index (stature over the cube root of weight) ranges from $10 \cdot 7$ for the plumpest to $14 \cdot 3$ for the most slender girl in the series. Preliminary analysis of variance showed significant differences in ponderal index, highly significant in height, between intakes, the means and standard deviations for which are set out in Table VI. Smallest mean statures occurred in the earliest intakes, the greatest in the 1964 and 1967 intakes; weight fluctuated slightly without any clear trend; ponderal index showed a barely detectable tendency to increase, girls becoming slightly more linear in physique. The multiple regression procedure was repeated, this time including ponderal index for the 1,886 girls for whom details of all variables are available.

Of the zero-order correlation coefficients set out in Table VII, there is very close similarity to those given in Table II for the full data. Ponderal index

TABLE VI

PHYSIQUE BY YEAR OF INTAKE

\begin{tabular}{|c|c|c|c|c|c|c|c|c|}
\hline & & \multicolumn{2}{|c|}{ Height (in) } & \multicolumn{2}{|c|}{ Weight (lb) } & \multicolumn{2}{|c|}{ Ponderal Index } & \multirow[b]{2}{*}{$\mathbf{n}$} \\
\hline \multicolumn{2}{|c|}{ Year } & Mean & SD & Mean & SD & Mean & SD & \\
\hline $\begin{array}{l}1959 \\
1960 \\
1961 \\
1962 \\
1964 \\
1967 \\
1968 \\
1969 \\
1970\end{array}$ & $\begin{array}{l}. \\
\ldots \\
\ldots \\
\ldots \\
\ldots \\
\ldots \\
\cdots\end{array}$ & $\begin{array}{l}63 \cdot 80 \\
63 \cdot 27 \\
63 \cdot 77 \\
63 \cdot 99 \\
64 \cdot 28 \\
64 \cdot 50 \\
63 \cdot 99 \\
64 \cdot 14 \\
64 \cdot 08\end{array}$ & $\begin{array}{l}2 \cdot 17 \\
2 \cdot 34 \\
2 \cdot 24 \\
2 \cdot 23 \\
2 \cdot 42 \\
2 \cdot 41 \\
2 \cdot 46 \\
2 \cdot 30 \\
2 \cdot 38\end{array}$ & $\begin{array}{l}126 \cdot 85 \\
127.91 \\
127.61 \\
126 \cdot 51 \\
128 \cdot 75 \\
128 \cdot 19 \\
126 \cdot 29 \\
128 \cdot 27 \\
125.96\end{array}$ & $\begin{array}{l}14 \cdot 56 \\
16 \cdot 86 \\
16 \cdot 49 \\
17.91 \\
18.91 \\
17.09 \\
17.33 \\
17.02 \\
16 \cdot 20\end{array}$ & $\begin{array}{l}12 \cdot 72 \\
12 \cdot 60 \\
12 \cdot 70 \\
12 \cdot 79 \\
12 \cdot 77 \\
12 \cdot 83 \\
12 \cdot 80 \\
12 \cdot 76 \\
12 \cdot 82\end{array}$ & $\begin{array}{l}0.40 \\
0.52 \\
0.48 \\
0.57 \\
0.52 \\
0 \cdot 53 \\
0 \cdot 50 \\
0 \cdot 52 \\
0 \cdot 51\end{array}$ & $\begin{array}{r}71 \\
77 \\
139 \\
160 \\
207 \\
321 \\
279 \\
299 \\
333\end{array}$ \\
\hline \multicolumn{2}{|l|}{$\mathbf{F}=$} & \multicolumn{2}{|c|}{$3 \cdot 10^{\mathrm{xxx}}$} & \multicolumn{2}{|c|}{0.86} & \multicolumn{2}{|c|}{$2 \cdot 56^{x}$} & $(8,1877 \mathrm{df})$ \\
\hline
\end{tabular}

TABLE VII

ZERO-ORDER CORRELATION COEFFICIENTS - 6 VARIABLE ANALYSIS

\begin{tabular}{|c|c|c|c|c|c|c|c|c|c|}
\hline & & & $\mathbf{x}_{1}$ & $\mathbf{X}_{\mathbf{2}}$ & $\mathbf{X}_{\mathbf{3}}$ & $\mathbf{x}_{4}$ & $\mathbf{X}_{\mathbf{5}}$ & $\mathbf{x}_{6}$ & $\mathbf{Y}$ \\
\hline $\mathbf{X}_{1}$ & Year of birth & .. & - & $\begin{array}{r}0.0754 \\
\pm 0.0229\end{array}$ & $\begin{array}{r}0.0434 \\
\pm 0.0230\end{array}$ & $\begin{array}{l}-0.1415 \\
\pm 0.0226\end{array}$ & $\begin{array}{r}0.0757 \\
\pm 0.0229\end{array}$ & $\begin{array}{r}0.9812 \\
\pm 0.0009\end{array}$ & $\begin{array}{r}0.0199 \\
\pm 0.0230\end{array}$ \\
\hline $\mathbf{X}_{3}$ & Position in sibship & .. & & & - & $\begin{array}{l}-0.0029 \\
\pm 0.0230\end{array}$ & $\begin{array}{l}-0.0049 \\
\pm 0.0230\end{array}$ & $\begin{array}{r}0.0454 \\
\pm 0.0230\end{array}$ & $\begin{array}{l}-0.0311 \\
\pm 0.0230\end{array}$ \\
\hline $\mathbf{x}_{6}$ & (Year of birth $)^{2}$ & .. & & & & & & - & $\begin{array}{r}0.0278 \\
\pm 0.0230\end{array}$ \\
\hline
\end{tabular}


shows a significant linear correlation with year of birth and with father's occupation, and a highly significant correlation with menarcheal age. These correlation coefficients with ponderal index are sufficiently high that taking them into account in a multiple regression analysis may well alter the effects of the other variables on menarcheal age. The partial regression coefficients are set out in Table VIII. Variations in ponderal index are seen to make the greatest contribution to variation in menarcheal age, followed by number of sibs and position in sibship. The linear and quadratic effects of year of birth diminish to a non-significant level. There is considerable increase in the multiple correlation coefficient $R=0 \cdot 2246$. It appears then that the differences in mean menarcheal age observed in the present series are associated with variations in physique, itself varying from year to year, and are presumably the product of the same factors.

Again, perhaps the change in composition of the sample from year to year may contribute. That height and weight vary from region to region of Britain has long been established (Beddoe, 1870; Roberts, 1953) and the general south-east to north-west gradient of diminishing height appears to hold in the Swansea subjects (Table IV), for breakdown by origin shows the greatest mean height and weight to occur in south-east England. They diminish northwards and westwards, and the lowest mean heights and weights occur in North Wales; the ponderal index does likewise (the three Scottish individuals are here neglected). The means weighted for regional representation (shown in Table V) suggest a slight increase in height and weight and a negligible change in ponderal index. The first is in the same direction as the observed means but does not quite coincide with them. It seems unlikely that secular trends in physique in the sample are to be attributed to changes in its composition, and in any case the secular and regional variation is already confounded in the material, in that the apparently greater stature, say, of south-east England may be due to the fact that the south-east England girls are predominan from the later, taller intakes, and so it is not possible to disentangle the effects. Certainly secular increase of one-fifth of an inch (0.5 over 12 years and three-quarters of a pound ( $0_{0} 3$ $\mathrm{kg}$ ) in the present intakes is not extreme by con parison with estimates of similar change from other samples elsewhere; for example, Aubenque (1937) examined university entrants from 1941 to 1951 and showed that the mean height of 20-year-otats over this period increased by approximately $1+5$ $\mathrm{cm}$.

\section{INTRA-COUNTY ANALYSIS}

To determine whether differential representation is entirely responsible for the trend in menarcheal age and body size, the analysis was repeated on the only county sufficiently well represented to allow an intra-county analysis, Glamorgan, which contributes 609 students to the total. For the five variable analysis (i.e., omitting ponderal ind the zero-order correlation coefficients and partial regression coefficients are set out in Fabje IX. The Glamorgan zero-order correlation coeffcients are very similar to those for the total material, only three non-significant coefficients changing their sign and remaining non-significa in the Glamorgan subsample. The Glamorg $\overline{\mathrm{B}} \mathrm{n}$ partial regression coefficients are all in the sa急e direction as those in the total material. Agam, that on social class is not significant, but this tip. the others are all highly so; the multiple correlatiơn coefficient $R=0.1701$. It appears that curvilinear trend within the Glamorgan material is more pronounced than in the total material.

Inclusion of the ponderal index (Table X) causes little change by comparison with these, though the multiple correlation coefficient rises appreciably, $R=0.2463$. The partial regression coefficie日st

TABLE VIII

PARTIAL REGRESSION COEFFICIENTS OF MENARCHEAL AGE ON EACH INDEPENDENT VARIATE-6 VARIABE

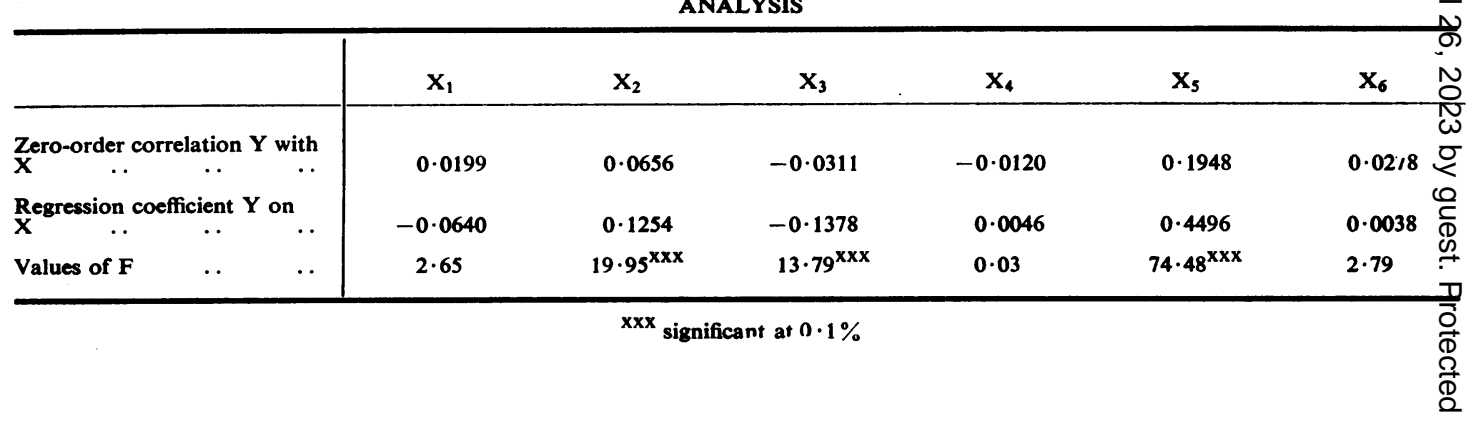


TABLE IX

ZERO-ORDER CORRELATION COEFFICIENTS-5 VARIABLE ANALYSIS

GLAMORGAN

\begin{tabular}{|c|c|c|c|c|c|c|}
\hline & & $\mathbf{X}_{1}$ & $\mathbf{X}_{2}$ & $\mathbf{X}_{\mathbf{3}}$ & $x_{4}$ & $\mathbf{Y}$ \\
\hline $\mathbf{x}_{1}$ & Year of birth $\quad$.. & - & $\begin{aligned} & 0.0765 \\
\pm & 0.040\end{aligned}$ & $\begin{aligned} & 0.0843 \\
\pm & 0.040\end{aligned}$ & $\begin{array}{l}-0.1293 \\
\pm 0.040\end{array}$ & $\begin{array}{l}-0.0427 \\
\pm 0.040\end{array}$ \\
\hline $\mathbf{X}_{2}$ & Number of sibs ... & & - & $\begin{array}{l}0.6204 \\
\pm 0.023\end{array}$ & $\begin{array}{l}-0.0255 \\
\pm 0.040\end{array}$ & $\begin{aligned} & 0.0674 \\
\pm & 0.040\end{aligned}$ \\
\hline $\mathbf{X}_{\mathbf{3}}$ & Position in sibship & & & - & $\begin{array}{l}-0.0104 \\
\pm 0.041\end{array}$ & $\begin{array}{l}-0.0398 \\
\pm 0.040\end{array}$ \\
\hline$X_{1}{ }^{2}$ & . & $\begin{aligned} & 0.9802 \\
\pm & 0.002\end{aligned}$ & $\begin{aligned} & 0.0839 \\
\pm & 0.040\end{aligned}$ & $\begin{array}{l}0.0926 \\
\pm 0.040\end{array}$ & $\begin{array}{l}-0.1319 \\
\pm 0.040\end{array}$ & $\begin{array}{l}-0.0207 \\
\pm 0.040\end{array}$ \\
\hline
\end{tabular}

Partial regression coefficients

\begin{tabular}{|c|c|c|c|c|c|c|}
\hline \multicolumn{4}{|c|}{$Y$ on } & $\mathbf{b}$ & SE & $\mathbf{F}$ \\
\hline $\mathbf{x}_{1}$ & Year of birth & .. & .. & $-0 \cdot 2046$ & 0.0725 & $7 \cdot 98^{x \times}$ \\
\hline $\mathbf{X}_{2}$ & Number of sibs & . & .. & $0 \cdot 1520$ & 0.0524 & $8 \cdot 43^{x \times}$ \\
\hline $\mathbf{X}_{\mathbf{3}}$ & Position in sibship & .. & $\cdots$ & $-0 \cdot 1856$ & 0.0711 & $6 \cdot 82^{x x}$ \\
\hline $\mathbf{x}_{4}$ & Father's occupation & .. & .. & -0.0175 & 0.0445 & 0.15 \\
\hline $\mathbf{X}_{1}{ }^{2}$ & .. & .. & .. & 0.0116 & 0.0044 & $7 \cdot 04^{x x}$ \\
\hline
\end{tabular}

TABLE X

ZERO-ORDER CORRELATION COEFFICIENTS- 6 VARIABLE ANALYSIS

GLAMORGAN
$(\mathbf{n}=476)$

\begin{tabular}{|c|c|c|c|c|c|c|c|c|}
\hline & & & $\mathbf{x}_{1}$ & $\mathbf{X}_{\mathbf{2}}$ & $\mathbf{X}_{\mathbf{3}}$ & $x_{4}$ & $x_{5}$ & $\mathbf{Y}$ \\
\hline $\mathbf{x}_{1}$ & Year of birth & .. & - & $\begin{array}{l}0.1013 \\
\pm 0.045\end{array}$ & $\begin{array}{l}0.0963 \\
\pm 0.045\end{array}$ & $\begin{array}{l}-0.1276 \\
\pm 0.045\end{array}$ & $\begin{array}{c}0.0625 \\
\pm 0.046\end{array}$ & $\begin{array}{l}-0.0371 \\
\pm 0.046\end{array}$ \\
\hline $\mathbf{x}_{2}$ & Number of sibs & $\cdots$ & & - & $\begin{array}{r}0.5942 \\
\pm 0.030\end{array}$ & $\begin{array}{l}-0.0356 \\
\pm 0.046\end{array}$ & $\begin{array}{l}0.0777 \\
\pm 0.046\end{array}$ & $\begin{aligned} & 0.0684 \\
\pm & 0.046\end{aligned}$ \\
\hline $\mathbf{x}_{\mathbf{3}}$ & Position in sibship & . & & & - & $\begin{array}{l}-0.0016 \\
\pm 0.046\end{array}$ & $\begin{aligned} & 0.0268 \\
\pm & 0.046\end{aligned}$ & $\begin{array}{l}-0.0187 \\
\pm 0.046\end{array}$ \\
\hline $\mathbf{x}_{4}$ & Father's occupation & .. & & & & - & $\begin{array}{l}-0.1139 \\
\pm 0.045\end{array}$ & $\begin{array}{r}0.0342 \\
+0.046\end{array}$ \\
\hline $\mathbf{x}_{\mathbf{s}}$ & Ponderal index & . & & & & & - & $\begin{array}{r}0.1860 \\
\pm 0.044\end{array}$ \\
\hline $\mathbf{X}_{1}^{2}$ & .. & .. & $\begin{aligned} 0.9851 \\
\pm 0.001\end{aligned}$ & $\begin{array}{c}\stackrel{0.1072}{ \pm \cdot 045} \\
\pm 0.04\end{array}$ & $\begin{array}{l}0.1072 \\
\pm 0.045\end{array}$ & $\begin{array}{l}-0.1362 \\
\pm 0.045\end{array}$ & $\begin{array}{c}0.0591 \\
\pm 0.046\end{array}$ & $\begin{array}{l}-0.0184 \\
\pm 0.046\end{array}$ \\
\hline
\end{tabular}

Partial regression coefficients

\begin{tabular}{|c|c|c|c|c|c|c|}
\hline & & & & $\mathbf{b}$ & $\mathbf{S E}$ & $\mathbf{F}$ \\
\hline $\mathbf{X}_{\mathbf{1}}$ & Year of birth & $\cdots$ & $\cdots$ & $-0 \cdot 2225$ & 0.083 & $7 \cdot 14^{x x}$ \\
\hline $\mathbf{X}_{2}$ & Number of sibs & . & $\cdots$ & $0 \cdot 1157$ & 0.058 & $3 \cdot 92^{x}$ \\
\hline $\mathbf{X}_{\mathbf{3}}$ & Position in sibship & . & . & -0.1337 & 0.080 & $2 \cdot 80$ \\
\hline $\mathbf{x}_{4}$ & Father's occupation & $\cdots$ & . & 0.0680 & 0.051 & $1 \cdot 81$ \\
\hline $\mathbf{X}_{\mathbf{5}}$ & Ponderal index & . & . & 0.4433 & $0 \cdot 105$ & $17 \cdot 87^{x \times x}$ \\
\hline$X_{1}{ }^{2}$ & $\cdots$ & . & . & 0.0127 & 0.005 & $6 \cdot 44^{x}$ \\
\hline
\end{tabular}


of menarcheal age on ponderal index is very highly significant, those on number of sibs and position in family diminish slightly, that (non-significant) on social class changes its sign, and the linear and quadratic on year of birth both increase slightly. The significance levels all decrease so that that on position in family is no longer significant and that on number of sibs barely so, but those on year of birth remain substantially significant. It appears, therefore, that within Glamorgan the $U$-shaped secular trend in menarcheal age is established, and though it is associated with changes in physique, it is by no means entirely accounted for by these. The Glamorgan results also suggest strongly that the findings in the total material are not to be attributed to changes in the regional composition of the intakes but represent a real phenomenon, the end of the downward secular trend in menarcheal age.

\section{Discussion}

There is little other information with which these findings can be compared. The results obtained by examination of the status quo on large samples of girls and subsequent analysis by probits are not directly comparable, though the results by one method may be adjusted to make them more comparable with the other (Fig. 2). Attention was drawn to the very close correspondence between the findings in the first seven years of this survey with the five status quo samples available for Britain for birth years from the mid-1930s to the mid-1940s (Roberts, 1971). There has been only one published status quo examination since (Roberts, Rozner and Swan, 1971). This appears to continue the upward

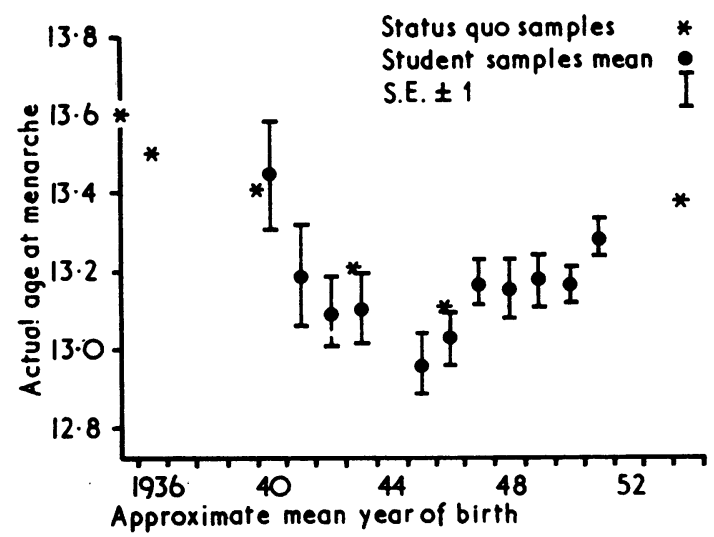

Fig. 2. Secular trend in menarche in Britain (recall samples are age corrected). trend suggested by the Swansea data now presented but it relates to a relatively poor industrial cor munity difficult to compare with the other samples. However, the suggestion that the secular downward trend in menarcheal age in Britain may have halted, at least temporarily, is compatible with what has been observed in studies of maturation in the United States (Zacharias, Wurtman, and Schatzoff, 1970); studies elsewhere in north-west Europe sugget that the trend is also coming to a halt in Norway (Brundtland and Walløe, 1973) but not in Sweden (Ljung, Bergsten-Brucefors, and Lindgren, 1974\%; in eastern Europe it still appears to be in progress (Eiben, 1970/1971). Any conclusion on a limited series of small samples spanning a limited period कf time such as the present study is tentative, and it desirable that data continue to be collected, both studies such as the present, carried out over a period, and also by examination of status quo samples. In particular, if the present findings are confirmed,oit will be important to establish whether menarcheal age is now getting later or whether it has achievecsa plateau.

The effect of family size on age at menacehe, demonstrated in the initial analysis of these gate. remains substantial. It has since been demonst fat in French-Canadian (Jenicek and Demirjian, 1574), in South Shields (Roberts et al, 1971), and in S9leth Indian girls (Singh, 1972). Nothing has emerged to negate the attribution of this to some envirenmental influence, such as nutritional hardship क्षेr standards of general care. The effect of position in family remains as strong in the total as in the fist seven years of the material but remains as inexplicable. Though sought, it did not emerge the South Shields or South Indian studies. If, as Frisch and her colleagues (Frisch and Revelle, 19 Frisch, 1972) maintain, menarche is related Fo critical weight or change in the body composition (Frisch, Revelle, and Cook, 1973) and if the family size effect is a reflection of poverty, then one may speculate that within a family of given size the youngest receives favoured treatment, producing a slight increase in the proportion of fat to lean boty weight. With this speculation, amenable to investigation by body composition studies of families, he physique results in the earlier part of this stydy (Dann and Roberts, 1969) do not conflict, for 虫e regression coefficients of weight and height con family size are negative, whereas those on position in family are positive.

As regards the absence of any association wojth socio-economic class, as identified by the RegistrarGeneral's classification of paternal occupation, The results are the same as in the initial analysis anforin 
the South Shields survey. In Finland, Kantero and Widholm (1971) found a significant relationship with paternal occupation, while in the French-Canadian study the effect was reversed, girls maturing later when their fathers were in the higher occupational groups. It is difficult to make comparisons between countries with different patterns of life, but certainly it seems that in Britain the environmental and particularly nutritional differences that distinguished the socio-economic classes and possibly influenced menarcheal age have today disappeared.

Finally, there emerges from this study, apart from the end of the downward secular trend and the confirmation of the occurrence, direction, magnitude, and independence of effect of all the other variables identified in the initial analysis, the remarkable indication of how little of the total variation in menarcheal age they account for when considered individually or together. The analysis incorporates as individual variates nearly all environmental factors currently held to influence menarcheal age, except direct measurement of nutrient intake. It is likely that other environmental variables would be similarly small or even smaller in influence. The variables excluding physique leave unexplained some $98.7 \%$ of the total variance in menarcheal age in the total material. Inclusion with them of the ponderal index leaves unexplained some $95 \%$ of the total variance. Exclusion of the regional differences by considering only the Glamorgan subsample gives respectively figures of $97 \%$ and $94 \%$ of the variance that remains unexplained. Johnston's 1974 review of the factors affecting menarcheal age concludes that 'the age at menarche is a developmental milestone which is highly variable, and highly sensitive to a variety of internal and external forces' which are exceedingly difficult to identify further. There is clearly scope for much further enquiry.

\section{REFERENCES}

AUBENQue, M. (1957). Note documentaire sur la statistique des tailles des étudiants au cours de ces dernières années. Biotypologie, 18, 202.

BEDDOE, J. (1870). On the stature and bulk of man in the British Isles. Mem. anthrop. Soc. Lond., 3, 384.

BRundtLand, G. H. and WaLløe, L. (1973). Menarcheal age in Norway. Nature (Lond), 241, 478.

DaNN, T. C. and Roberts, D. F. (1969). Physique and family environment in girls attending a Welsh College. Brit. J. prev. soc. Med., 23, 65.
- and -. (1973). End of the trend? A 12-year study of age at menarche. Brit. med. J., 3, 265.

EIBEN, O. G. (1970/1971). Genetische und demographische Faktoren und Menarchealter. Anthropologischer Anzeiger, 33, 205.

Frisch, R. E. (1972). Weight at menarche. Pediatrics, 50, 445.

— and Revelle, R. (1970). Height and weight at menarche and a hypothesis of critical body weights and adolescent events. Science, 169, 397.

$\longrightarrow$, - and CoOK, S. (1973). Components of weight at menarche and the initiation of the adolescent growth spurt in girls. Hum. Biol., 45, 469.

JeniceK, M. and Demirjian, A. (1974). Age at menarche in French-Canadian urban girls. Ann. hum. Biol., $1,339$.

Johnston, F. E. (1974). Control of age at menarche. Hum. Biol., 46, 159.

KANTERo, R. L. and Widholm, O. (1971). The age of menarche in Finnish girls in 1969. Acta Obstet. Gynec. Scand., 50, Suppl. 14, pp. 7-18.

LJUNG, B., Bergsten-BruCefors, A., and Lindgren, G. (1974). The secular trend in physical growth in Sweden. Ann. hum. Biol., 1, 245.

ROBERTS, D. F. (1953). Body weight, race and climate. Amer. J. phys. Anthrop., 11, 533.

(1971). A long term investigation of maturational age. Proceedings Ales Hrdlicka Congress. pp. 115122. Czechoslovakian Academy of Sciences,

- and DANN, T. C. (1967). Influences on menarcheal age in girls in a Welsh College. Brit. J. prev. soc. Med., 21, 170.

- Rozner, L. M., and Swan, A. V. (1971). Age at menarche, physique and environment in industrial north-east England. Acta. paediat. scand., 60, 158.

SiNGH, H. D. (1972). Family size and age of menarche. Amer. J. Obstet. Gynec., 114, 837.

TANNER, J. M. (1955). Growth at Adolescence, 1st ed. Blackwell Scientific Publications, Oxford.

(1962). Growth at Adolescence, 2nd ed. Blackwell Scientific Publications, Oxford.

(1965). The trend towards earlier physical maturation. In Biological Aspects of Social Problems, edited by J. E. Meade and A. S. Parkes, pp. 40-65. Oliver and Boyd, Edinburgh.

Zacharias, L., Wurtman, R. J., and Schatzoff, M. (1970). Sexual maturation in contemporary American girls. Amer. J. Obstet. Gynaec., 108, 833.

Requests for reprints to: Dr. D. F. Roberts, Department of Human Genetics, The University, 19 Claremont Place, Newcastle-upon-Tyne NE2 4AA. 